\title{
ОЦЕНКА ПЕРСПЕКТИВ НАУЧНОГО И ПРАКТИЧЕСКОГО ПОТЕНЦИАЛА КОМПЛЕКСНОЙ ПЕРЕРАБОТКИ ЖИВЫХ ЭЛЕМЕНТОВ ДЕРЕВА ДЛЯ МОДЕРНИЗАЦИИ ЛЕСОПРОМЫШЛЕННОГО КОМПЛЕКСА
}

\author{
() С.А. Медведева, С.С. Тимофеева, И.В. Волчатова* \\ Иркутский государственный технический университет, ул. Лермонтова, 83, \\ Иркутск, 664074 (Россия), e-mail: genesis@istu.edu
}

Выполнен анализ отечественных научно-исследовательских и прикладных разработок по изучению и использованию живых элементов дерева, некоторых биотехнологий, в том числе разработок авторов; дана оценка перспективы их развития для инноваций лесохимической и целлюлозно-бумажной промышленности (ЦБП). Обсуждены новые перспективные направления биорефайнинга, связанные с использованием биологически активных соединений, выделенных из низкокачественной древесины и живых элементов дерева, в качестве синтонов, и биотехнологии переработки крупнотоннажных твердых отходов и очистки сбросов ЦБП, способных решить проблему утилизации некоторых накопленных отходов, значительно снизить экологический ущерб, наносимый этой отраслью промышленности. Отмечено, что современные отходы лесозаготовительного производства способны стать источником получения дорогостоящих, высокоэффективных продуктов, имеющих большой спрос на рынке.

Ключевые слова: лесохимическая промышленность, живые элементы дерева, биорефайнинг, компостирование, фитотехнологии.

\section{Введение}

Организация производства комплексной и глубокой химической переработки лесных ресурсов в настоящее время далека от принципов рационального природопользования. Целлюлозно-бумажная промышленность (ЦБП), являясь одной из стратегических и социально значимых отраслей экономики России, для получения целлюлозы использует только древесину. При этом большая часть заготавливаемой древесины вывозится за рубеж. Для сравнения, в Финляндии и Швеции вывозят в основном продукцию из древесины, подвергнутой глубокой химической переработке (соответственно 60 и 70\%). Объем заготовок в этих странах в два с лишним раза меньше, чем в России, а валютная выручка от экспорта в 2,5 раза больше. Финляндия, располагая 0,5\% лесных ресурсов планеты, дает 25\% мирового экспорта целлюлозно-бумажной продукции, в то время как Россия, располагая $21 \%$ мировых запасов леса, дает менее $1 \%$ экспорта этой продукции [1]. К тому же при заготовке древесины имеют место большие потери древесного сырья на лесозаготовках (в среднем 25\% от рубки, или до 40 м $^{3}$ на 1 га ликвидной древесины), в процессе транспортировки и первичной переработки леса на нижних складах. Ежегодно в местах заготовки древесины в лесу остаются и практически не используются хвоя, ветви, масса которых достигает 15\% массы стволовой древесины. Кроме того, на лесосеках остаются корни деревьев, а на местах переработки древесины - опилки, кора. Так, например, на территории Иркутской области, в экономике которой лесопромышленный ком-

Медведева Светлана Алексеевна - профессор кафедры промышленной экологии и БЖД, доктор химических наук, e-mail: jrsam@mail.ru

Тимофеева Светлана Семеновна - заведующая кафедрой промышленной экологии и БЖД, доктор технических наук, професcop, e-mail: bgd@ istu.irk.ru Волчатова Ирина Владимировна - доцент кафедры промышленной экологии и БЖД, кандидат биологических наук, e-mail: genesis@istu.edu плекс занимает одно из ведущих мест, в 2008 г. было заготовлено 30,9 млн м ${ }^{3}$ ликвидной древесины и не использовано около 1 млн м ${ }^{3}$ вторичного древесного сырья [2]. По России экономически доступные ресурсы только древесной зелени оцениваются специалистами в 20-30 млн т в год, а степень их использования не превышает 10-15\%. Остальная масса в виде

\footnotetext{
* Автор, с которым следует вести переписку.
} 
отходов захламляет места вырубок и первичной переработки древесины, переходя в категорию накопленного экологического ущерба.

Одним из направлений оптимального пути достижения экологического и ресурсосберегающего эффекта в ЦБП считается внедрение наилучших доступных технологий: нормирование негативного воздействия на окружающую среду должно основываться на базе технологий, отвечающих последним экономически доступным достижениям науки при минимальном уровне воздействия на экосистемы. Учитывая то, что стратегической задачей модернизации ЦБП и лесопромышленного комплекса в целом является создание инновационных проектов глубокой химической и комплексной переработки лесных ресурсов, в данном обзоре мы рассмотрели технологии, в том числе и разработки авторов, перспективные для развития комплекса лесохимической промышленности и ЦБП, оценив их научно-технический потенциал и российский опыт.

\section{Технология биорефайнинга}

Под биорефайнингом понимают комплексную переработку древесного сырья с превращением его основных компонентов в товарные продукты с высокой добавленной стоимостью. Главные направления развития биорефайнинга - использование биомассы дерева для получения не только волокнистых полуфабрикатов, но и биологически активных соединений живых элементов дерева, а также органического субстрата для синтеза новых видов биотоплива как возобновляемого источника энергии.

Мировая тенденция последних лет - использование природных соединений в качестве сырья для получения лекарственных, ветеринарных препаратов, косметических и парфюмерных товаров, средств защиты человека и животных. Вещества, созданные природой в ходе длительного эволюционного развития, легче усваиваются организмом, обладают более мягким физиологическим действием по сравнению с синтетическими аналогами и зачастую лишены вредных побочных эффектов последних. Древесное сырье (низкокачественная древесина, кора, древесная зелень, в первую очередь преимущественно вырубаемых хвойных пород) как возобновляемое растительное сырье представляет собой неисчерпаемый источник и может быть дешевым исходным сырьем для получения многих ценных природных биологически активных веществ.

Для разработки комплексного использования древесного растительного сырья в России созданы все предпосылки. Начало развитию этого направления было положено работами советских исследователей еще в послевоенные годы [3, 4]. Основы фундаментальных исследований комплексного использования древесины, живых элементов дерева, химического состава их экстрактивных веществ закладываются в нашей стране в 60-е годы прошлого века, прежде всего в Ленинграде (Лесотехническая академия им. С.М. Кирова - ЛТА; в настоящее время Санкт-Петербургская государственная лесотехническая академия им. С.М. Кирова - СПбГЛТА) и Риге (Институт химии древесины АН ЛатвССР, НПО «Силава»). Исследовался химический состав экстрактивных веществ всех компонентов древесины и древесной зелени, разрабатывались подходы и отдельные технологии в схемах комплексного использования древесного сырья [5] и древесной зелени [6]. Многие разработки уже давно доведены до технологического уровня и внедрены в производство. Например, из древесины получают активные древесные угли, таловое масло, скипидар и его составляющие камфору, камфен, терпинеол и др., практическая значимость которых хорошо известна.

Достаточно широк комплекс композиционных продуктов из древесной зелени: это витаминная мука, хвойные эфирные масла, хвойный экстракт, хлорофилло-каротиновая паста, хлорофиллин натрия, провитаминный концентрат, хвойный воск, органическое удобрение, многие из которых по разработанным технологиям выпускались на лесохимических заводах и НПО. В 1984 г. в СССР работало более 10 заводов по переработке древесной зелени, которые располагались в европейской части страны, самый старый из них Тихвинский лесохимический завод - работал с 1931 года [6].

В разработку этого направления включаются многие научно-исследовательские институты страны, в частности Ленинграда (ВНИИ гидролиза растительных материалов, ВНПОБумпром), Москвы (Московский государственный университет им. М.В. Ломоносова - МГУ; институт биохимии им. А.Н. Баха АН СССР, теперь - институт биохимии им. А.Н. Баха РАН), Горького (Центральный научноисследовательский и проектный институт лесохимической промышленности - ЦНИЛХИ), Алма-Аты (Казахский государственный университет, теперь - Казахский национальный университет им. аль-Фараби).

Создается мощная исследовательская база в Сибирском регионе - головные институты Новосибирска (Новосибирский институт органической химии им. Н.Н. Ворожцова СО РАН - НИОР СО РАН), Иркутска (Иркутский институт органической химии им. А.Е. Фаворского СО РАН, теперь - Институт химии им. А.Е. Фаворского СО РАН - ИрИХ СО РАН), Красноярска (Институт леса им. В.Н. Сукачева; Институт химии природного органического сырья СО РАН - теперь Институт химии и химической технологии СО 
РАН - ИХХТ СО РАН), где закладываются основы фундаментальных исследований химического состава сибирского растительного сырья, его комплексного использования, и в первую очередь древесины, живых элементов дерева и их экстрактивных веществ. Здесь осуществляется тесное взаимодействие академической и вузовской науки, налажено взаимодействие с предприятиями ЛПК. За время работы этими организациями накоплены значительные научные и технологические заделы в области переработки древесного сырья, а также осуществляется подготовка квалифицированных специалистов, что очень важно для организации полноценного развития этого направления. Формируются научные школы: в Новосибирске под руководством д.Х.н., профессора, заслуженного деятеля науки РСФСР В.А. Пентеговой (защищено 16 кандидатских и три докторских диссертации), в Иркутске - под руководством д.х.н., профессора, заслуженного деятеля науки РФ Н.А. Тюкавкиной (защищены докторская и 15 кандидатских диссертаций).

В НИОХ СО РАН в результате многолетнего комплексного исследования был изучен состав живиц 30 видов хвойных деревьев, произрастающих в различных уголках Советского Союза, показаны особенности химического состава представителей различных родов и видов, многие терпеновые соединения выделены впервые. Разработаны и внедрены технологии получения иммерсионного масла для микроскопии, а также кедровый и пихтовый бальзамы для микротехники [7]. По оптическим свойствам кедровый бальзам, производившийся из сибирского кедра, был равноценной заменой импортируемому канадскому бальзаму. Эти разработки были внедрены на Барнаульском канифольно-терпентинном заводе.

В ИрИХ СО РАН с 1960-х гг. проводятся исследования компонентного химического состава фенольных экстрактивных веществ древесины, хвои, коры хвойных растений Восточной Сибири и Дальнего Востока (пихты, лиственницы, ели, сосны). С 1979 г. работа выполнялась совместно с Московской медицинской академией им. И.М. Сеченова - ММА (теперь Первый Московский медицинский университет им. И.М. Сеченова - ПМГМУ). В течение 1968-1973 гг. эта работа поддерживалась Техническим управлением Министерства целлюлозно-бумажной промышленности СССР в рамках выполнения темы «Создание технологии комплексного химического использования лиственницы в целлюлозном производстве».

В целенаправленном комплексном исследовании органически сочетались теоретические и практические проблемы, решение которых было обеспечено благодаря широкому сотрудничеству со многими научными и производственными учреждениями и вовлечению большого круга специалистов различных профессий. В результате многоплановых исследований установлен компонентный состав фенольных экстрактивных древесины и хвои сибирских хвойных пород, идентифицировано около 100 индивидуальных фенольных соединений, для новых - установлено строение. Разработаны подходы к выделению как доминирующих биологически активных веществ - мальтола [8], пиносильвина [9], дигидрокверцетина, арабиногалактана [10], так и композиций в ряду фенолокислот, флавоноидов, стильбенов, лигнанов, ацетофенонов и их гликозидов [10].

Для некоторых соединений были предложены технологические схемы выделения, которые могли совмещаться с уже существующими рабочими технологиями. Так, выделение мальтола (антиоксидант из хвои пихты) можно совмещать с технологией получения пихтового масла [11], опытная проверка была проведена в Чусовском леспромхозе Пермской области. Получение стильбенов (пиносильвин, обладает бактериостатической и фунгистатической активностью) из древесины сосны совмещается с технологией получения канифоли [12], для пиносильвина был разработан лабораторный технологический регламент и в НИОХ СО РАН получена опытная партия. Для промышленного получения арабиногалактана - иммуномодулятора, обладающего мембранотропными свойствами [13], и дигидрокверцетина - антиоксиданта, проявляющего капилляро-, радиопротекторные свойства [14], из древесины лиственницы совместными работами ИрИОХ СО РАН, красноярского Института леса им. В.Н. Сукачева и ЛТА был разработан технологический регламент и проект полузаводской установки (Сибгипробум, Иркутск).

Эти полномасштабные исследования, выполненные на высоком научном уровне, представляют мощную теоретическую и практическую базу для разработки новых технологических схем переработки низкокачественной древесины и древесной зелени. Они уже послужили более глубокому развитию биорефайнинга - разработке новых высокоэффективных биологически активных препаратов нового поколения, в том числе комбинаторного действия.

В ПМГМУ им. И.М. Сеченова в тесном взаимодействии с рядом научных учреждений, и прежде всего с Всероссийским научно-исследовательским институтом лекарственных и ароматических растений (ВИЛАР), на основе дигидрокверцетина создан новый отечественный фитопрепарат диквертин, обладающий широким спектром биологического действия, в том числе антиоксидантным и капилляропротекторным [15], который выпускается теперь рядом отечественных фирм по усовершенствованным технологиям [16-18]. 
На основе диквертина в ПМГМУ им. И.М. Сеченова совместно с НИИ фармакологии Томского научного центра СО РАМН созданы препараты асковертин и саливертин. Асковертин - это композиция диквертина и аскорбиновой кислоты, которая по гемореологическому действию не уступает известным препаратам тренталу и танакану. Саливертин - композиция диквертина и ацетилсалициловой кислоты. Диквертин в этой композиции, проявляя антиоксидантные свойства, обладая гемореологическим и гастропротекторным действием, практически нейтрализует побочные эффекты действия ацетилсалициловой кислоты [19].

На основе арабиногалактана [20] в ИрИХ СО РАН синтезирован и совместно с НИ противочумным институтом Сибири и Дальнего Востока, Иркутским государственным медицинским университетом (ИГМУ) изучен железосодержащий препарат - «феррогал». Согласно полученным результатам, он не только проявляет антианемическую активность, но и сохраняет мембранотропные свойства, иммуномодуляторную активность арабиногалактана и, кроме того, обладает пролонгированным действием в отличие от известных лекарственных форм железосодержащих препаратов [21, 22].

В настоящее время в ИрИХ СО РАН сформировано и успешно развивается новое направление создание наноразмерных материалов различной природы с использованием в качестве наностабилизирующих матриц природных полисахаридов и в первую очередь, арабиногалактана [23, 24].

Примером достаточно продвинутой идеологии биорефайнинга может служить разработанная в ИрИХ СО РАН схема безотходной комплексной переработки биомассы лиственницы сибирской и даурской, которая из древесины и коры позволяет получить большую серию дорогостоящих веществ: дигидрокверцетин, арабиногалактан, кристаллическую глюкозу (при ее сбраживании - спирт), воск, натуральный краситель, дубильные вещества, полифепан, активные угли. Для отдельных блоков этой схемы разработаны технологические регламенты, создана опытная установка, наработаны опытные партии продуктов из древесины и коры [25].

Таким образом, совершенно очевидно, что возможности технологий биорефайнинга очень велики, поскольку они позволяют получить дорогостоящие, высокоэффективные продукты, имеющие большой спрос на рынке, из дешевого сырья, являющегося отходом лесозаготовительного производства. Эти продукты могут быть достойными конкурентами имеющихся синтетических и природных аналогов и востребованы в пищевой промышленности, в медицине и косметике. Их производство может быть высокоприбыльным и рентабельным. Использование технологий комплексной переработки древесного сырья позволит снизить техногенные загрязнения, повысить экологическую безопасность и рентабельность производства в целом.

Однако, несмотря на мощный научный потенциал, имеющиеся технологии получения продуктов из древесного сырья пока не позволяют достичь того уровня развития этой отрасли, который имеется в западных странах. Очевидным препятствием масштабной переработки древесной зелени и низкокачественной древесины является незначительный объем товарной продукции в общем объеме лесохозяйственных и лесопромышленных предприятий, необходимость дополнительных капиталовложений и трудовых ресурсов, а также все еще недостаточная изученность химического состава живых элементов дерева и их биологической активности.

\section{Биотехнологии утилизации лигноцеллюлозных отходов}

Большую проблему для лесопромышленного комплекса представляют многотоннажные лигноцеллюлозные отходы гидролизной (гидролизный лигнин), целлюлозно-бумажной (шлам-лигнин) и лесохимической промышленности (опилки, щепа). Особенно остро стоит эта проблема в Иркутской области, где одного гидролизного лигнина накоплено свыше 2 млн т, а шлам-лигнина только в накопителях ОАО «Селенгинский ЦКК» содержится 3,5 млн м³ зации этих осадков сжиганием крайне нерациональна, поскольку полностью теряется органическая составляющая этих отходов. В институтах СО РАН разработаны экологически рациональные способы утилизации этих отходов.

В Лимнологическом институте СО РАН (ЛИН СО РАН) совместно с Институтом географии им. В.Б. Сочавы СО РАН (ИГ СО РАН) разработан способ совместного компостирования отходов целлюлознокартонного комбината (шлам-лигнина Селенгинского ЦКК), ТЭЦ и животноводческих комплексов. Эти компосты оказывают благоприятное влияние на плодородие почв и урожай сельскохозяйственных культур [27].

В ИрИХ СО РАН и в Иркутском государственном техническом университете - ИрГТУ (теперь Национальный исследовательский Иркутский государственный технический университет - НИ ИрГТУ) разработаны технологии микробиологической ускоренной переработки лигноцеллюлозных отходов, которые позволяют получить одновременно ценное органо-минеральное удобрение и ликвидировать многотоннаж- 
ные отходы гидролизной, целлюлозно-бумажной и лесохимической промышленности. Процессы ускоренного компостирования основаны на введении в субстрат (гидролизный лигнин, древесные опилки, шламлигнин) «закваски» в виде ассоциации непатогенных микроорганизмов [28].

Масштабные опыты на полях Иркутской государственной сельскохозяйственной академии (ИрГСХА), ФГУ «Центр агрохимической службы «Иркутский», опытных хозяйств Иркутской области и Архангельского края показали, что применение органо-минерального удобрения из гидролизного лигнина и древесных опилок дает высокую (на 30-60\%) прибавку урожая ячменя, пшеницы, гороха, овса и зеленой массы кукурузы. При этом ни в продукции, ни в почвах не отмечено появления тяжелых металлов. Анализ агрохимических показателей почвы свидетельствует о том, что внесение компоста способствует накоплению в почве подвижного фосфора, обменного калия, нитратного азота и гумуса, улучшает структуру почв, возвращает деградированным землям плодородное состояние [29, 30].

В НИ ИрГТУ с целью переработки шлам-лигнинов разработан метод вермикомпостирования с использованием дождевых или красных калифорнийских червей. Вермикомпосты отличаются высоким структурированием и высоким содержанием гуминовых кислот. Испытания на полях ИрГСХА показали, что при внесении в почву вермикомпостов прибавка урожая зерновых достигает 75\% [31].

Технологии микробиологического компостирования позволяют одновременно решить несколько проблем: проблему экологически рационального использования лигноцеллюлозных отходов (вернуть органическую составляющую в естественный круговорот веществ), расширить ассортимент органоминеральных удобрений, содержащих питательные элементы, основная часть которых находится в усваиваемой растениями форме. Они с успехом могут использоваться при рекультивации земель как сельскохозяйственного, так и лесохозяйственного назначения.

\section{Фитотехнологии в целлюлозо-бумажной промышленности}

Этим термином обозначают защитно-восстановительные мероприятия для окружающей среды с использованием растительности. В последнее время в практике внедрения экобиозащитных технологий, обеспечивающих сохранение окружающей среды, все чаще стали применяться именно фитотехнологии.

Особенностью метода является его легкая привязка к месту действия. Метод может применяться непосредственно на загрязненном участке или же отдельно для обработки неплотного грунта, шламов или отложений, загрязненных вредными веществами. Одно из явных преимуществ очистных сооружений с использованием фитотехнологии - это их долговечность, которая обеспечивается почти полным отсутствием металлических частей, подвергающихся коррозии, а также насосного оборудования, так как роль насосов выполняют сами растения. Самотечное движение очищаемой воды обеспечивает очистным сооружениям на основе фитотехнологии почти неограниченный период эксплуатации. Разработки и внедрение фитотехнологий успешно осуществляются как за рубежом, так и в нашей стране [32-34]. Площадки, на которых используются фитотехнологии, в разных странах получили различные названия: Constructed wetland, Reed bed, Artificial wetland, биоплато, биоинженерные сооружения, ботанические площадки и т.п.

В НИ ИрГТУ более 30 лет ведутся исследования по разработке и внедрению фитотехнологий очистки сточных вод и обезвреживания отходов в условиях резко континентального климата [34-36]. Изучены механизмы обезвреживания гидатофитами в регионах Сибири и Севера более 100 компонентов сточных вод различных отраслей промышленности, в том числе целлюлозно-бумажной. Из большого числа водных растений отобраны виды, обладающие наиболее высоким уровнем ферментативной активности и скоростями биодеструкции, которые рекомендуются для посадки на гидроботанических очистных сооружениях для обезвреживания тех или иных загрязняющих веществ. Эти работы создали базу знаний о взаимодействиях загрязняющих веществ с макрофитами, которые важны для создания научных основ фиторемедиации и практического использования фитотехнологий. Сегодня они позволяют оценивать новые результаты исследований фиторемедиационного потенциала макрофитов.

\section{Заключение}

Выполненный анализ научно-исследовательских и прикладных разработок по исследованию и использованию живых элементов дерева, а также некоторых биотехнологий свидетельствует о том, что уже созданная мощная научно-исследовательская база раскрыла многосторонние перспективные направления применения выделенных полезных природных продуктов и синтезированных на их основе новых соединений. Разработанные и научно обоснованные биотехнологии утилизации крупнотоннажных твердых отхо- 
дов и сбросов ЦБП, по сути, уже решают проблему утилизации и переработки накопленных отходов, значительно снижая экологический ущерб, наносимый этой отраслью промышленности.

Исходя из того, что основной стратегией Европейского союза является создание инновационных проектов, в том числе многоцелевое использование лесных ресурсов для производства из отходов новых продуктов, надо полагать, что важной составляющей государственной социально-экономической политики страны будет повышение эффективности использования научных разработок и внедрение в производство новых инновационных экотехнологий. В ближайшее время преобразование и дальнейшее развитие лесопромышленной отрасли однозначно будет связано с развитием ее научно-технического потенциала, разработкой и внедрением новых технологий на всех этапах переработки древесного сырья, с использованием всех компонентов дерева и вторичного сырья, которые позволят создать экономически выгодные, экологические безопасные предприятия нового типа, обеспечивающие тесную связь лесозаготовительной, лесохимической отраслей и целлюлозно-бумажных комбинатов. В отличие от современного этапа развития производства, в конечные продукты будут полностью перерабатываться отходы производства.

\section{Список литературы}

1. Ткачев С.В. Развитие целлюлозно-бумажной промышленности Сибири и Дальнего Востока // Целлюлоза. Бумага. Картон. 2001. №3-4. С. 8-10.

2. О состоянии и об охране окружающей среды Иркутской области в 2009 г. Гос. доклад. Иркутск, 2010. 585 с.

3. Калниньш А.И., Аболиньш Я.Т. Новое в использовании древесной коры, хвои и листьев. М., 1958. 29 с.

4. А.с. 68796 (СССР). Способ комплексной переработки хвои / Ф.Т. Солодкий / БИ. 1947. №7.

5. Комплексное использование древесного сырья. Рига, 1984. 318 с.

6. Ягодин В.И. Основы химии и технологии переработки древесной зелени. Л., 1981. 224 с.

7. Пентегова В.А. Исследование живиц хвойных семейства Pinaceae : дис. ... д-ра хим. наук. Новосибирск, $1971.320 \mathrm{c}$

8. Медведева С.А. Исследование фенольных соединений хвои некоторых видов пихты и лиственницы : дис. ... канд. хим. наук. Новосибирск, 1973. 138 с.

9. Луцкий В.И. Фенольные соединения древесины кедра сибирского (Pinus sibirica) и сосны обыкновенной (Pinus silvestris) : дис. ... канд. хим. наук. Новосибирск, 1971. 120 с.

10. Тюкавкина Н.А. Исследование фенольных соединений некоторых видов семейства Ріпасеае : дис. ... д-ра хим. наук. Иркутск, 1973. 393 с.

11. А.с. 515744 (СССР). Способ выделения 2-окси-3-метил-4-пирона / Н.А. Тюкавкина, С.А. Медведева, С.3. Иванова, Г.В. Коровкина, А.Д. Сафонова / БИ. 1976. №20.

12. А.с. 425893 (СССР). Способ получения монометилового эфира пиносильвина / Н.А. Тюкавкина, В.И. Луцкий, Н.М. Бородина, В.А. Пентегова, А.И. Лисина, Г.Н. Першин, А.Л. Микерина / БИ. 1974. №16.

13. А.с. 303877 (СССР). Способ получения арабиногалактана / Н.А. Тюкавкина, Г.Ф. Антонова / БИ. 1975. №10.

14. А.c. 351847 (СССР). Способ выделения дигидрокверцетина / Н.А. Тюкавкина, Г.Ф. Антонова / БИ. 1975. №10.

15. Патент 2014841 (РФ). Антиоксидантное, капилляропротекторное, противовоспалительное и антигистаминное средство / С.Я. Соколов, Н.А. Тюкавкина, В.К. Колхир, Ю.А. Колесник, А.П. Арзамасцев, Н.П. Глазова, В.А. Зюзин, А.И. Багинская, В.А. Бабкин, Л.А. Остроухова / БИ. 1994. №12.

16. Патент 2000797 (РФ). Способ выделения дигидрокверцетина / В.А. Бабкин, Н.А. Тюкавкина, Л.А. Остроухова, Ю.К. Святкин, С.Я. Соколов / БИ. 1993. №37.

17. Патент 2034559 (РФ). Способ выделения дигидрокверцетина / В.А. Бабкин, Ю.К. Святкин, Л.А. Остроухова, В.В. Глазырин, В.Г. Воробьев, Н.А. Тюкавкина / БИ. 1995. №13.

18. Патент 2038094 (РФ). Способ получения дигидрокверцетина / Н.А. Тюкавкина, В.В. Наумов, Ю.А. Колесник, И.А. Руленко, В.Е. Ручкин, Т.Ф. Гаврилова, В.В. Наумов / БИ. 1994. №18.

19. Плотников М.Б., Тюкавкина Н.А., Плотникова Т.М. Лекарственные препараты на основе диквертина. Томск, 2005. $224 \mathrm{c}$.

20. Патент 2040268 (РФ). Способ получения арабиногалактана / Н.А. Тюкавкина, Ю.А. Колесник, В.В. Наумов, И.А. Руленко / БИ. 1994. №21.

21. Дубровина В.И., Медведева С.А., Александрова Г.П., Тюкавкина Н.А., Голубинский Е.П., Иванова Т.А., Коновалова Ж.А. Иммуномодулирующие свойства арабиногалактана лиственницы сибирской // Фармация. 2001. №5. C. 26-27.

22. Медведева С.А., Александрова Г.П., Дубровина В.И., Четверикова Т.Д., Грищенко Л.А., Красникова И.М., Феоктостова Л.П., Тюкавкина Н.А. Арабиногалактан лиственницы - перспективная полимерная матрица для биогенных металлов // Химия и компьютерное моделирование. Бутлеровские сообщения. 2002. №2. С. 45-49.

23. Грищенко Л.А. Металлосодержащие нанокомпозиты на основе арабиногалактана : дис. ... канд. хим. наук. Иркутск, 2007. 167 с.

24. Трофимов Б.А., Сухов Б.Г., Александрова Г.П., Медведева С.А., Грищенко Л.А., Малькина А.Г., Феоктистова Л.П., Сапожников А.Н., Дубровина В.И., Мартынович Е.Ф., Тирский В.В., Семенов А.Л. Нанокомпозиты с 
магнитными, оптическими, каталитическими и биологически активными свойствами на основе арабиногалактана // Доклады Академии наук. 2003. Т. 393, №5. С. 1-2.

25. Бабкин В.А., Остроухова Л.А., Дьячкова С.Г., Святкин Ю.К., Бабкин Д.В., Онучина Н.А. Безотходная комплексная переработка биомассы лиственниц сибирской и даурской // Химия в интересах устойчивого развития. 1997. №5. С. 105-115.

26. О состоянии окружающей природной среды Иркутской области в 1996 г. Гос. доклад. Иркутск, 1997. 230 с.

27. Куликова Н.Н., Сутурин А.Н., Антоненко А.М., Бойко С.М., Парадина Л.Ф. Органо-минеральные компосты из отходов целлюлозно-бумажной промышленности и их влияние на плодородие почв // Почвоведение. 1996. №7. C. 905-910.

28. Патент 2192403 (РФ). Способ получения органо-минерального удобрения / И.В. Волчатова, С.А. Медведева, Э.И. Коломиец, А.Г. Лобанок / БИ. 2002. №31.

29. Волчатова И.В., Медведева С.А., Новикова Л.Н., Серышев В.А. Исследование свойств органо-минерального удобрения на основе гидролизного лигнина // Агрохимия. 2000. №12. С. 67-71.

30. Волчатова И.В., Медведева С.А. Влияние компоста на основе гидролизного лигнина на продуктивность пшеницы в условиях полевого опыта // Вестник ИрГСХА. 2012. Вып. 48. С. 28-33.

31. Тимофеева С.С., Скороходова Е.Т. Биоконверсия осадков сточных вод методом компостирования и ферментативная активность продуктов // Социальные проблемы инженерной экологии, природопользование и ресурсосбережение: сб. матер. науч. конф. Красноярск, 1996. С. 75-83.

32. Остроумов С.А., Соломонова Е. А. Изучение фиторемедиационного потенциала водных растений // Экология окружающей среды и безопасность жизнедеятельности. 2006. №6. С. 63-68.

33. McCutcheon S., Wolfe N.L., Carreria L., Ou T. Phytoremediation of hazardous wastes // Proc. National Conf. Innovative technologies for site remediation and hazardous waste management. Pittsburgh, 1995. Pp. 597-604.

34. Timofeeva S.S., Stom D.I. Present and perspectives of using hydrobotanic treatment for sewage waters // Acta Hydrochim. Hydrobiol. 1986. Vol. 16, N3. Pp. 299-312.

35. Тимофеева С.С., Бейм А.М. Закономерности трансформации лигнинных веществ в водоемах Восточной Сибири // Водные ресурсы. 1990. №2. С. 115-120.

36. Тимофеева С.С., Бейм А.М. Роль макрофитов в обезвреживании хлорированных фенолов // Водные ресурсы. 1992. №1. C. 89-191.

Поступило в редакциюю 21 октября 2012 2.

\section{Medvedeva S.A., Timofeeva S.S, Volchatova I.V.* EVALUATION PERSPECTIVES OF SCIENTIFIC AND PRACTI- CAL POTENTIAL COMPLEX TREATMENT OF LIVING CELLS FOR MODERNIZATION TIMBER PROCESSING COMPLEX.}

Irkutsk State Technical University, Lermontova st., 83, Irkutsk, 664074 (Russia), e-mail: genesis@istu.edu

The analysis of national and applied research to study and use of living elements of wood, some biotechnologies, including the development of the authors. It was assessed prospects of development for innovation resin industries, pulp and paper industry. Discussed a new promising directions of biorefinery with using of biologically active compounds, which were produced from low-quality wood and living trees of elements, as synthons. Discussed biotechnologies processing of large solid waste and cleaning pulp and paper industry, that can solve the problem of disposal of certain wastes, reduce the ecological damage caused by this industry. It was noted, that a modern logging waste production can be a source of produce costly, highperformance products that there are in great demand in the market.

Keywords: resin industry, the living elements of wood, biorefinery, composting, phytotechnology.

\footnotetext{
* Corresponding author.
} 


\section{References}

1. Tkachev S.V. Tselliuloza. Bumaga. Karton, 2001, no. 3-4, pp. 8-10. (in Russ.).

2. O sostoianii i ob okhrane okruzhaiushchei sredy Irkutskoi oblasti v 2009 g. gos. doklad. [On the state and Environmental Protection of the Irkutsk region in 2009, a government report]. Irkutsk, 2010, 585 p. (in Russ.).

3. Kalnin'sh A.I., Abolin'sh Ia.T. Novoe v ispol'zovanii drevesnoi kory, khvoi i list'ev. [New-to-use tree bark, pine needles and leaves]. Moscow, 1958, 29 p. (in Russ.).

4. Inventors certificate 68796 (USSR). 1947. (in Russ.).

5. Kompleksnoe ispol'zovanie drevesnogo syr'ia. [Comprehensive utilization of raw wood]. Riga, 1984, 318 p. (in Russ.).

6. Iagodin V.I. Osnovy khimii i tekhnologii pererabotki drevesnoi zeleni. [Fundamentals of chemistry and technology of processing wood greens]. Leningrad, 1981, 224 p. (in Russ.).

7. Pentegova V.A. Issledovanie zhivits khvoinykh semeistva Pinaceae : dis. ... d-ra khim. nauk. [Study oleoresin coniferous family Pinaceae: Novosibirsk, 1971. 320 p. (in Russ.).

8. Medvedeva S.A. Issledovanie fenol'nykh soedinenii khvoi nekotorykh vidov pikhty i listvennitsy : dis. ... kand. khim. nauk. [Study of phenolic compounds of some species of pine needles of fir and larch: Ph.D. in Chemistry dissertation]. Novosibirsk, 1973, 138 p. (in Russ.).

9. Lutskii V.I. Fenol'nye soedineniia drevesiny kedra sibirskogo (Pinus sibirica) $i$ sosny obyknovennoi (Pinus silvestris) : dis. ... kand. khim. nauk. [Phenolic compounds of Siberian cedar wood (Pinus sibirica) and Scots pine (Pinus silvestris): Ph.D. in Chemistry dissertation]. Novosibirsk, 1971, 120 p. (in Russ.).

10. Tiukavkina N.A. Issledovanie fenol'nykh soedinenii nekotorykh vidov semeistva Rinaceae : dis. ... d-ra khim. nauk. [Study of phenolic compounds of some species of the family Rinaceae: dissertation of the doctor of chemical sciences]. Irkutsk, 1973. 393 c. (in Russ.).

11. Inventors certificate 515744 (USSR). 1976. (in Russ.).

12. Inventors certificate 425893 (USSR). 1974. (in Russ.).

13. Inventors certificate 303877 (USSR). 1975. (in Russ.).

14. Inventors certificate 351847 (USSR). 1975. (in Russ.).

15. Patent 2014841 (RU). 1994. (in Russ.).

16. Patent 2000797 (RU). 1993. (in Russ.).

17. Patent 2034559 (RU). 1995. (in Russ.).

18. Patent 2038094 (RU). 1994. (in Russ.).

19. Plotnikov M.B., Tiukavkina N.A., Plotnikova T.M. Lekarstvennye preparaty na osnove dikvertina. [Medications based Diquertin]. Tomsk 2005, 224 p. (in Russ.).

20. Patent 2040268 (RU). 1994. (in Russ.).

21. Dubrovina V.I., Medvedeva S.A., Aleksandrova G.P., Tiukavkina N.A., Golubinskii E.P., Ivanova T.A., Konovalova Zh.A. Farmatsiia, 2001, no. 5, pp. 26-27. (in Russ.).

22. Medvedeva S.A., Aleksandrova G.P., Dubrovina V.I., Chetverikova T.D., Grishchenko L.A., Krasnikova I.M., Feoktostova L.P., Tiukavkina N.A. Khimiia i komp'iuternoe modelirovanie. Butlerovskie soobshcheniia, 2002, no. 2, pp. 45-49. (in Russ.).

23. Грищенко Л.А. Металлосодержащие нанокомпозиты на основе арабиногалактана : дис. ... канд. хим. наук. [Metal-based nanocomposites arabinogalactan : Ph.D. in Chemistry dissertation]. Irkutsk, 2007, 167 p. (in Russ.).

24. Trofimov B.A., Sukhov B.G., Aleksandrova G.P., Medvedeva S.A., Grishchenko L.A., Mal'kina A.G., Feoktistova L.P., Sapozhnikov A.N., Dubrovina V.I., Martynovich E.F., Tirskii V.V., Semenov A.L. Doklady Akademii nauk, 2003, vol. 393, no. 5, pp. 1-2. (in Russ.).

25. Babkin V.A., Ostroukhova L.A., D'iachkova S.G., Sviatkin Iu.K., Babkin D.V., Onuchina N.A. Khimiia v interesakh ustoichivogo razvitiia, 1997, no. 5, pp. 105-115. (in Russ.).

26. O sostoianii okruzhaiushchei prirodnoi sredy Irkutskoi oblasti v 1996 g. gos. doklad. [On the state and Environmental Protection of the Irkutsk region in 1996, a government report]. Irkutsk, 1997, 230 p. (in Russ.).

27. Kulikova N.N., Suturin A.N., Antonenko A.M., Boiko S.M., Paradina L.F. Pochvovedenie, 1996, no. 7, pp. $905-910$. (in Russ.).

28. Patent 2192403 (RU). 2002. (in Russ.).

29. Volchatova I.V., Medvedeva S.A., Novikova L.N., Seryshev V.A. Agrokhimiia, 2000, no. 12, pp. 67-71. (in Russ.).

30. Volchatova I.V., Medvedeva S.A. Vestnik IrGSKhA, 2012, no. 48, pp. 28-33. (in Russ.).

31. imofeeva S.S., Skorokhodova E.T. Sotsial'nye problemy inzhenernoi ekologii, prirodopol'zovanie $i$ resursosberezhenie: sb. mater. nauch. konf. [Social problems of environmental engineering, environmental management and resource conservation: compendium of scientific conference]. Krasnoyarsk, 1996, pp. 75-83. (in Russ.).

32. Ostroumov S.A., Solomonova E.A. Ekologiia okruzhaiushchei sredy i bezopasnost' zhiznedeiatel'nosti, 2006, no. 6, pp. 63-68. (in Russ.).

33. McCutcheon S., Wolfe N.L., Carreria L., Ou T. Proc. National Conf. Innovative technologies for site remediation and hazardous waste management. Pittsburgh, 1995, pp. 597-604.

34. Timofeeva S.S., Stom D.I. Acta Hydrochim. Hydrobiol., 1986, vol. 16, no. 3, pp. 299-312.

35. Timofeeva S.S., Beim A.M. Vodnye resursy, 1990, no. 2, pp. 115-120. (in Russ.).

36. Timofeeva S.S., Beim A.M. Vodnye resursy, 1992, no. 1, pp. 89-191. (in Russ.). 